\title{
To the Future, and Beyond!
}

\section{Richard Hoefer ${ }^{1}$}

Accepted: 3 March 2021 / Published online: 12 March 2021

(c) The Author(s), under exclusive licence to Springer Nature Switzerland AG 2021

Many of the situations we find ourselves in now were unimaginable 12 months ago. That is the power of a pandemic that has killed over 500,000 Americans and over 2.5 million around the world. The number of confirmed nonlethal cases is over 115 million (https://www.worldometers.info/coronavirus/coronavirus-death-toll/) (as of March 3, 2021).

In addition, the American political system has weathered the first non-peaceful transition of power in its history, the result of a preplanned "Big Lie" that claimed the election was "rigged" and "stolen." State-level Republican parties are submitting bills to restrict voting rights. There is so much to be worried about and concerned for not only in the USA but in many other locations around the world.

Still, power transition did occur, and the duly elected Democratic candidate, Joseph R. Biden, was sworn in. Viewers were treated to wonderful singing and poetry to mark the day. Two members of the Democratic party were elected to the US Senate from Georgia, a state so reliably Republican that this result was considered all but impossible.

I know the pull to look at the worst of 2020 is strong, but positive aspects of social work values and the daily dig into retail politics are still happening. This is not the time to retreat, though it is important to join with others of like-minds so that no one is left to themselves in the movement for positive outcomes.

Part of the hope for 2021 for the Journal of Policy Practice and Research is to expand our efforts to shape the future. In this regard, we are soliciting short articles relating to the idea of "where do we go, next?" As noted on the Journal's Web site (https://www.springer.com/journal/42972/updates/18864836):

Richard Hoefer

rhoefer@uta.edu

1 School of Social Work, University of Texas At Arlington, Box 19129, Arlington, TX 76019, USA 


\section{Call for Papers: a New Federal Administration: New Policy Practice and Research Directions?}

The Journal of Policy Practice and Research announces a call for contributions to a special issue with the theme A New Federal Administration: New Policy Practice and Research Directions?

Contributions are solicited for a special issue that recognizes that in the USA, we have a new administration at the national level. We seek to look forward with an issue that presents what leading and emerging scholars see as promising avenues to explore in relationship to policy practice and research in this new era. We seek to accept forward-looking thought pieces that look at the possibilities of where we go from here.

We recognize the difficulties in changing directions from policies and practice enacted in recent years, and the continuing presence of the Trump-leaning Republicans in the legislative branch at all levels of government in the USA.

The question each contribution should address is what can and should social work policy practitioners do? What policies are most likely to move government or private entities in a more social justice-oriented direction? How can social work as a profession and social workers as individuals spark change? What approaches will work when government is so divided? How do we overcome the deep divisions in society along racial lines, and other fault lines in society? How do we successfully defend the rights of all marginalized people, particularly as "culture wars" are being used to discriminate on the basis of "freedom of religion"?

Details:

- Contributions are due by June 30, 2021.

- Each submission should be 5-8 pages long, double spaced, including references.

- These will fall under the heading of conceptual articles so a considerable amount of speculation and opinion is allowed; still, they need to be grounded in literature.

Topics might include:

- How does policy practice change in times of deep political division?

- How does policy theory respond to gridlock in government?

- If you were advising the Biden administration in a particular area of policy (mental health, healthcare, income support, aging, etc.), what would you suggest they should do?

- What are implications of the continuing COVID pandemic in your policy area of expertise? What needs to be done to lessen the impact on vulnerable populations? 
On to this issue's articles,

I am extraordinarily pleased with the group of articles included in this issue. We have an array of theory-based manuscripts, including the use of the Civic Voluntarism Model to compare US and Swiss social workers' political participation. This is a striking cross-national comparison of a model that deserves even more testing, not just description. How can we turn the information into a path forward to increasing civic voluntarism and engagement within the bounds of traditional participation? Does this model fall apart in the face of white supremacists, QAnon conspiracy adherents who do not operate in the same world of facts as most people, and others who vow to use violence to ensure they grab more power? These are questions for us all to ponder and work on.

Pritzker looks at one of the most common issues that social workers, especially students, run into when encountering the political system and the "sausage-making" that is how policy is created: how can one maintain attachment to the social work Code of Ethics? The struggles student interns (and others) face when encountering the maelstrom of questionable behavior needs to be dealt with and understood more deeply. Do we risk a revolt in the face of reality, or do we, as social work educators, carve out ways to keep cynicism at bay? What are some of our best ideas for doing so? What theory helps us here?

Radohl looks at what happens in social work membership organizations-how do social workers participate? Where do they find opportunities and challenges as they work on this aspect of the professional career?

These three articles are nicely grouped together to explore the political realms of "policy practice" more than policy details. These are important works and, together, look at important questions I hope other authors and researchers pick up and add their own answers.

Barrick's work on committee hearings and how witness affiliations impact testimony with the debate over the Violence Against Women Act is a deeply detailed look at the importance of small details in the larger currents of policy-making. It reminds us that it is not only the vast sweeps of history that cause policy shifts, but also working in and around the small details of advocacy.

We have more wonderful work to be published in the near future! Remember to think about how you want to help shape the future of policy making and policy practiceturn in your manuscript for the special contribution noted earlier.

Publisher's Note Springer Nature remains neutral with regard to jurisdictional claims in published maps and institutional affiliations. 